\title{
Abortion, Persons, and Futures of Value
}

\section{Donald Wilson}

I

In a very widely anthologized article, Don Marquis offers an argument claiming to establish that the "overwhelming majority of deliberate abortions are seriously immoral" (Marquis 1989, 183). Like many who argue against abortion, Marquis assumes the immorality of killing adult human beings and proceeds to argue that consistency requires us to judge abortion in the same way. Unlike other arguments, however, Marquis's argument focuses on the harm done in killing rather than on the moral status of the fetus. Familiarly, many anti-abortion arguments begin with the assumption that it is wrong to kill adult human beings and proceed to argue that, since the fetus is a human being, it must also ordinarily be wrong to kill it. In doing so, these arguments take for granted that adult human beings are members of the moral community entitled to direct moral consideration and assume that this status extends to the fetus in virtue of its shared humanity. The standard problem here is that we are likely to agree that it is at least conceptually possible that there may be other beings who could have moral rights and obligations but are not biologically human. If so, it cannot simply be our biological humanity that entitles us to claim this status. Critics of these arguments therefore claim we need a distinct term - person - to indicate moral standing, and argue that standard arguments emphasizing fetal humanity obscure this important issue and, by wrongly conflating being human and being a person, fail to establish the immorality of abortion.

By focusing on an analysis of the harm done in death, Marquis claims he can avoid this problem and advance discussion of the issue beyond what he claims are merely dogmatic 
assertions about the moral status of the fetus. Analyzing the harm involved in death, he suggests that:

When I am killed, I am deprived both of what I now value that would have been part of my future personal life, and what I would come to value. Therefore when I die, I am deprived of all the value of my future. Inflicting this loss on me is ultimately what makes killing wrong. This being the case, it would seem that what makes killing any adult human being prima facie seriously wrong is the loss of his or her future (Marquis 1989, p. 190).

And, turning to the abortion issue, he claims that the implications of this analysis are clear:

The future of a standard fetus includes a set of experiences, projects, activities, and such that are identical with the futures of young children. Since the reason that it is sufficient to explain why it is wrong to kill human beings after the time of birth is a reason that also applies to fetuses, it follows that abortion is prima facie seriously morally wrong (Marquis 1989, p. 192).

Marquis takes this analysis of the harm in death to be obvious and emphasizes that his argument takes no position on the contentious issue of moral status. The central significance of his argument is then said to lie it its affording us a persuasive argument against abortion that successfully circumvents the issue of fetal humanity or personhood:

This way of dealing with the problem of abortion seems superior to other approaches to the ethics of abortion because it rests on an ethics of killing which is close to self-evident, because the crucial morally relevant property clearly applies to fetuses, and because the argument avoids the usual equivocations on "human life," "human being," or "person" (Marquis, 1989 p. 202).

Marquis goes on to claim various other advantages for this account emphasizing that it leaves open the possibility that it could be wrong to kill non-human beings (aliens and animals) if it can be shown that they experience the same kind of loss in death and that this view is therefore not an arbitrarily anthropocentric one. In particular, contrasting his analysis with personhood accounts like Mary Ann Warren's ${ }^{1}$ and Joel Feinberg's ${ }^{2}$ that define moral status in terms of the possession of higher some set of higher cognitive capacities, he emphasizes that his view readily 
allows us to regard infanticide as directly and seriously morally wrong and argues that the failure of personhood accounts to do so is a central flaw in these approaches.

Drawing on material in a reply that Marquis makes to one of his critics, I claim that Marquis fails to offer a plausible and generally persuasive argument against abortion. I argue that any claim to plausibility depends essentially on details about the value said to be lost in death details that Marquis argues he can forgo. I then claim that any attempt to provide the detail necessary to warrant the claim of plausibility will inevitably be tantamount to an account of moral status and can be expected to have all the familiar problems of inclusion and exclusion associated with such accounts. In the absence of some specific and plausible account of the value lost in death, I conclude that there is no reason to think of this as a plausible general argument against abortion. Finally, I reconsider the standard problem infanticide poses for personhood accounts. I argue that Marquis' use of this objection as a blanket criticism of personhood accounts is superficial but that standard indirect accounts of the wrong of infanticide offered by personhood models like Warren's are likely to entail at least some restrictions on the availability of abortion.

\section{II}

In an article critical of Marquis's "futurist account," Gerald Paske ${ }^{3}$ agrees that the loss of a future like ours is morally significant and that this loss is involved in our sense of the harm done in killing. Paske stresses, however, that we do not think of the loss of just any future in this way:

Marquis is correct when he offers the "unproblematic assumption" that "it is wrong to kill us." But though the assumption is unproblematic, it requires explication. Indeed if we are to avoid "human chauvinism" and "species bias," this unproblematic assumption must be explicated. Why is it that a future-like-ours is the one that counts and not - say - the future of a pig or a cow? (Paske, p. 363) 
Paske claims that the answer to this question "lies in the concept of personhood" (Pojman, p. 363) and that Marquis' account therefore presupposes some notion of personhood in singling out the futures of human beings for special consideration:

Persons, and only persons, can conceptualize a distant future in which they are a participant. Only persons can anticipate and deliberately shape their own future. Only persons can desire and possess the freedom to shape their own self, their own life, their own future ..... One aspect of the seriousness of death for a person is the loss of an anticipated, intended, longedfor-future. No non-person can be harmed in this way. It is the loss of this sort of a future that constitutes a common - but not a universal - harm arising from death. Thus, the harms constituted by the loss of our future presupposes that we are persons (Paske, p. 364).

Although he acknowledges that the quality of the future lost in death affects our judgment of the extent of harm suffered, Paske therefore argues that the central harm in killing consists in the "immediate loss of personhood" (Pakse, p. 364). He goes on to claim that, unlike Marquis' view, this account can capture our sense that the wrong involved in deliberate killing is not diminished in cases where natural death is imminent anyway.

It seems to me that Paske is correct in focusing on the underlying question of moral status but what interests me here is Marquis' reply to Paske ${ }^{4}$ and the striking way in which it emphasizes the intended generality of Marquis' argument. Discussing Paske's criticism, Marquis stresses that his "future like ours" [FLO] account is deliberately agnostic on the question of what makes our futures valuable and specifically claims that a more detailed account is not required for the argument against abortion. He contrasts a future-as-a-person account [FAP] that thinks of the harm in killing in terms of the loss of a future involving the exercise of various higher cognitive capacities with a future-of-enjoyment account [FOE] that associates this harm with the loss of enjoyable experiences. His FLO account, he claims, is deliberately neutral between these alternatives and can be interpreted in either way: 
There is room under the FLO umbrella for both the FAP and the FOE view. The FAP account and the FOE account each entail the FLO account, but the FLO account entails neither (Marquis, 1998, p. 374).

On either account, however, the fetus will suffer the same harm in death that an adult does, and both accounts will therefore entail the impermissibility of abortion. Accordingly, Marquis concludes that:

if one is interested in constructing the most plausible account one can of the wrongness of abortion, there is no need to commit oneself in an overly specific way on the issue of just what it is about our futures that makes them valuable (Marquis, 1998, p. 374).

The claim, then, is that a FLO account of the wrong of abortion can be endorsed from within a variety of different perspectives, making this approach a plausible one with broad general appeal. Any substantive claim to general plausibility, however, now depends on the plausibility of the underlying views and the assumption that there is a range of promising alternative analyses of the central notion of a valuable future that will support Marquis' position on abortion. At a minimum, the claim to plausibility rests on our having some reason to suppose that there is at least one generally promising analysis of the value at issue in a FLO account that supports his view. There are, however, good reasons to doubt that this is the case and to think, instead, that any claim to plausibility here must rest on precisely the detail that Marquis claims he can forgo.

An account of the morality or immorality of an act seeks to justify a moral claim by appeal to argument, and arguments do not typically gain in plausibility by vagueness. In particular, the broader implications of arguments are significant, and critical discussion of them is common in questioning the plausibility of arguments - indeed, this is exactly the strategy that Marquis himself adopts in raising the specter of infanticide in discussing personhood accounts. The different accounts Marquis considers involve very different arguments for the impermissibility of 
abortion, and the agreement he emphasizes masks very substantive disagreement between them, both with respect to the nature of the harm done and the scope of any obligations to avoid it. In particular, both of these accounts have implications that go well beyond the discussion of abortion and, in each case these implications raise significant questions about the plausibility of the underlying accounts.

Take the future-of-enjoyment account. On this view, the harm done in death consists in the individual being deprived of a future of enjoyable experiences. The first and obvious implication here is one that Marquis acknowledges - while it will still be wrong to kill adult human beings and fetuses, it will also be wrong to kill cows and pigs. More generally, this view also clearly has implications that will extend well beyond concerns with killing to include a broad range of concerns with our general treatment of other sentient life in farming, animal experimentation etc. Concerns like these will require profound changes in our present patterns of life and will require these changes on just the same grounds as any prohibition of abortion. Whatever one makes of this view, these implications are obviously significant and controversial and must cast doubt on Marquis' claim to the self-evident plausibility of his "future like ours" account when interpreted in this way.

Equally familiar problems are just as quickly apparent in the more limiting future-as-a-person account. Recall that on this account it is the loss of a future involving the exercise of higher cognitive capacities that constitutes the harm done in death. The first and obvious difficulty here mirrors the infanticide problem of personhood accounts in emphasizing that FAP accounts will objectionably minimize the harm done in certain kinds of killing. A full FAP account will need to specify the relevant experiences that make up a future of value for persons (reflection, friendship, love, or some set of experiences unique to beings capable of higher cognitive 
function). However these are specified, some human beings - people with severely impaired mental functioning, for example - are not going to be capable of these experiences and will not therefore be wronged if they are killed ${ }^{5}$. In addition, Paske emphasizes that identifying the harm of death and the wrongness of killing with the loss of a future of experiences like this suggests that they are lessened in the case of older persons facing shorter futures with correspondingly less value. Paske claims that while we might think that the length of an expected future is relevant in cases where we find ourselves forced to choose between saving a young person and an old one, we do not think that the murder of an old person is less wrong than that of a younger one.

Interestingly, Marquis replies to this objection referring to it as "Paske's most important argument for the importance of the concept of a person" (Pojman, 379) and, in doing so, is quickly forced to provide the kind of further detail he earlier claims we can forgo. Responding to this problem, Marquis proposes a subjective account of the value assigned to future experiences according to which the value of a future is a function of the agent's own subjective valuing of their experiences (presumably both the value they presently attach to things and the value they may reasonably be expected to attach to experiences in the future). Citing the comments of an aging colleague, he suggests that "people who are approaching death often remark on how much more they treasure life because they realize how little of it is left," and, generalizing this remark, claims that "the value of each day of a person's future from her own point of view varies directly with age" (Pojman, 380). The idea, then, is that differences in the length of a person's future will be offset by different perceptions of the value of this future and hence, as Marquis puts it, "the values of our futures as a whole tend toward equality" (Pojman, 380). 
This subjective valuing account is a problematic reply for several reasons and does not, in any case, solve the problem. Notwithstanding the experience of Marquis' colleague, we might plausibly think that a large number of elderly people experience depression when confronted with immanent mortality and failing health in the latter stages of their lives. Reflecting on their diminished capacities and circumstances and comparing these with their past situations, they may well attach relatively less value to their futures. If so, this reply will do little to reduce worries about marginalization in this kind of FLO account. Moreover, even if the general claim is accepted, there will be people who do not presently value their own experiences and who cannot reasonably be expected to do so in the future (people who are chronically depressed or who for whatever reason do not value their lives). Even granting Marquis his broad claim about the differing values assigned to futures, these individuals will remain objectionably marginalized by this version of an FLO account ${ }^{6}$, again suggesting that the claim to obvious plausibility is in doubt.

To be clear, these concerns obviously do not suffice to show that a FLO account of the wrong in killing is doomed to fail. What they do show, however, is that an account like this cannot be said to succeed without further discussion, and that the detail Marquis claims is unnecessary is, in fact, essential if the claim of plausibility is to be sustained. Any FLO account assumes some explanation of the moral significance of our being deprived of a specific kind of future. The FOE and FAP accounts are naturally suggested here because they identify a subject of loss who is deprived of something plausibly regarded as a good. As such, the problems with these accounts considered above are significant and must cast doubt on the claim to self-evident plausibility Marquis makes on behalf of the FLO account. 
More importantly, these problems suggest that there is every reason to think that similar questions of scope and inclusion will arise in relation to other possible accounts of the value of our futures. It is no accident that the FLO accounts considered so far seem heir to the same problems of scope and inclusiveness commonplace in discussions of abortion that start directly with the question of moral standing and seek to define this standing in terms of the possession of some set of capacities (sentience, consciousness, rationality, etc.). FLO accounts associate the harm in death with the loss of valuable future experiences and therefore presuppose some account of the good involved in these experiences. Any specification of this good indirectly confers moral status on beings capable of experiencing it (if only as loci of good realization or production). So, for example, if we think of the value of a future in terms of the pleasure it will contain, we assume that pleasure is good and beings capable of experiencing it then become the focus of moral concern.

The deeper problem here is therefore that any further specification of the value at stake in an FLO account is tantamount to a claim to moral standing on behalf of beings capable of appreciating the value in question and, as such, any FLO account can be expected to confront all the same deep and persistent problems of scope and exclusion familiar in more direct accounts of moral status ${ }^{7}$. If so, there is no reason to assume that there is a range of obvious and plausible analyses of the central notion of a future of value that will support Marquis' view of abortion or even that there is any such analysis. Instead, there is every reason to think that a FLO account cannot hope to make a plausible argument for any position on abortion without engaging the same underlying complexity and detail that confronts direct accounts of moral status. 


\section{III}

While Marquis' argument might, then, gain in persuasiveness by forgoing detail, his claim to self-evidence and obvious plausibility masks familiar and significant difficulties and his account will inevitably be drawn into the same kind of deep and troubling underlying issues of scope and exclusion associated with more direct accounts of moral status. I want to end, therefore, with some remarks on one very prominent case of exclusion that Marquis uses extensively as a general criticism of personhood accounts of moral standing. These personhood accounts understand moral status in terms of the possession of some set of relatively high level cognitive capacities and are often said to be naturally suggested by the intuition that in order to count directly from the moral point of view a being must be invested in its life as a conscious project. Like other commentators, Marquis emphasizes that any attempt to justify abortion on the grounds that the fetus lacks capacities like these will also justify infanticide. Assuming we agree that infanticide is morally wrong, we are then to conclude that this analysis of moral status and the approach to an ethics of killing it entails must be defective. I have argued that Marquis' account cannot forgo the kind of details likely to raise similar issues of exclusion, and I want to suggest in closing that his treatment of this particular case of exclusion is superficial. The personhood account can, I claim, accommodate significant moral and legal prohibitions on infanticide but, interestingly, only in a way likely also to entail some restrictions on abortion.

Citing Joel Feinberg's response as an example, Marquis claims that personhood strategists have failed consistently to deal with the serious problem of apparently licensing infanticide. Feinberg defends what he calls a "commonsense" view of moral status that emphasizes the actual possession of cognitive capacities associated with the capacity to care about the direction one's life takes: 
In the commonsense way of thinking, persons are those beings who, among other things, are conscious, have a concept and awareness of themselves, are capable of experiencing emotions, can reason and acquire understanding, can plan ahead, can act on their plans, and can feel pleasure and pain (Regan, 1980, p. 189).

He acknowledges that this view has the clearly counterintuitive implication that infanticide will not then involve any direct moral wrong (since the early infant, like the fetus, is not relevantly a person endowed with moral rights). Responding to this problem, Feinberg emphasizes the normally very deep instinctive concern that humans have for infants in general and argues that the utility of this concern gives us reason to preserve it and hence to prohibit infanticide:

The moral rule that condemns these killings and the legal rule that renders them punishable are both supported by "utilitarian reasons," that is, considerations of what is called "social utility," "the common good," "the public interest," and the like. Nature has apparently implanted in us an instinctive tenderness toward infants that has proven extremely useful to the species, not only because it leads us to protect our young from death, and thus keep our population up, but also because infants usually grow into adults, and in Benn's words, "if as infants they are not treated with some minimal degree of tenderness and consideration, they will suffer for it later, as persons." ${ }^{6}$ One might add that when they are adults, others will suffer for it too, at their hands. Spontaneous warmth and sympathy toward babies then clearly has a great deal of social utility, and insofar as infanticide would tend to weaken that socially valuable response, it is, on utilitarian grounds, morally wrong (Regan, 1980, p. 198).

In response, Marquis argues that the utility calculation could go the other way - that we might be better off in the long run by selectively culling infants deemed unlikely to be useful and productive members of society. In doing so, however, he burdens the personhood theorist in general with a narrowly utilitarian approach to moral reasoning that they need not share, and one that would be just as damning to his own view. We could, after all, interpret the FOV account in a similarly consequentialist vein and argue that we should promote lives likely to result in more valuable experiences and marginalize those unlikely to do so. 
Like Marquis' FOV account, the personhood model need not be understood in consequentialist terms and responses similar to Feinberg's can then be seen as more robust than Marquis suggests. Marquis is right when he argues that the options available to personhood theories are limited: Given obvious developmental similarities, any account of personhood that excludes the fetus is also going to exclude the newborn and, very likely, early infants. The options for personhood accounts concerned to prohibit infanticide but permit abortion are therefore limited to the kind of indirect approach taken by commentators like Feinberg, Warren, and others. Unless, however, we take the fact that moral status is afforded only indirectly as being sufficient in itself to justify rejection of this approach, the adequacy of this kind of response will turn on the seriousness attaching to any indirectly motivated moral concern. Freed from the simple utilitarian model of moral reasoning that Marquis imposes on his opponents, these accounts have more to offer in this regard than his analysis suggests and there is therefore more to be said in response to this issue.

The interest that normal adults have in the well being of children - especially those who have children of their own - is surely among the deepest and most profound of human interests. Both by nature and nurture, most normal adults are uniquely and very seriously disturbed by thoughts of child abuse, neglect, sexual exploitation and other harms and these concerns are not typically compartmentalized and limited only to their own children (it is precisely for this reason that charities routinely use images of children in distress to encourage giving, that dramas frequently feature children in horrific situations, etc.). Indeed, opponents of personhood accounts like Marquis rely on just this kind of intuitively deep disapprobation in claiming that the exclusion and marginalization of infants is a sufficient reason to reject this type of approach. 
Any moral concern for infants motivated on this basis, though still indirect, can therefore be understood to be a very significant one warranting serious moral and legal censure. Moreover, indirect but significant moral concerns like this are not uncommon in moral thinking. Take, for example, the interest that many people have in religious or spiritual concerns. The fact that people have these interests and attach great weight to them is taken to give others moral reasons to respect their practices, and the respect and accommodation required of us need not be understood on consequentialist grounds. So, for example, it is precisely because of the deep significance of religion in human life that moral and legal rights to liberty or autonomy are typically thought to extend to especially robust and important protections in these areas of life. When we think of moral and legal prohibitions on infanticide as having their origin in human interests that are at least as deep as these, then, we can reasonably regard this kind of indirect account can as generating serious moral and legal concerns.

I take it that any adequate indirect account of the moral impermissibility of infanticide must be grounded in a deep interest of this sort, and I assume that this is the kind of response that Mary Ann Warren has in mind in the postscript appended to her well-known article on abortion. With Warren in mind, however, one caveat is worth mentioning.

Warren argues that the permissibility or otherwise of abortion turns on the question of whether the fetus is a full member of the moral community entitled to the same rights and protections as other members of this community. Like Feinberg, she defines moral status in terms of the possession of some relatively high level cognitive capacities, arguing that a being with direct moral status must be capable of at least one of the following: consciousness, reasoning, self-motivated activity, sophisticated communication, self-awareness (though not necessarily individual). Again like Feinberg, she immediately concedes that her account of 
personhood will exclude newborns and early human infants and argues that they will count in moral deliberation indirectly on the basis of the concerns of other persons with their well-being. In doing so, however, Warren considers an obvious objection to this kind of indirect status reply according to which any indirect moral concern robust enough to motivate significant moral and legal censure in the case of infanticide will also extend to restrictions on abortions. After all, it is surely also true that a large number of people care just as deeply about the well being of fetuses and do not think of this interest as distinct from the concern they have for newborns and infants.

Warren responds to this problem by arguing that unlike constraints on infanticide, restrictions on abortion motivated by the indirect concern of others for the well being of fetuses will encroach on the mother's rights. So, for example, just as it is one thing to protect an un-owned wilderness area on the basis of deep concern for its preservation but quite another to force the owners of land to preserve it for the sake of these interests, there is a similarly important difference between limiting what we can do to newborns on the basis of deep concerns for their well-being and forcing women to carry fetuses to term against their will. Reasoning in this way, she concludes that we can consistently prohibit infanticide while routinely permitting abortion.

This is, however, premature. The problem is that the adequacy of the personhood response in the case of infanticide turns on the strength and depth of the interest adult humans are assumed to have in the well-being of newborns. We do not think of infanticide as a minor wrong. We think of it as a deep and grievous moral wrong, and it is precisely this widely shared intuition that the objection leverages. An adequate response must capture this and, given the form of personhood accounts, they can only hope to account for this indirectly by emphasizing the natural depth and significance of the kind of normal human interest in the well-being of children described above. 
If so, Warren cannot then simply assume that the woman's rights will obviously always trump the very same profound interests in the case of many people who are also deeply invested in the well being of fetuses. In the first place, it is not clear that limited restrictions on the form that late-term abortions can take would violate the mother's rights. We might, for example, limit the types of abortion procedure allowed to those that would deliver the fetus whole and healthy, arguing that we are justified in doing so on the grounds of the very profound interest of other persons in the well-being of the fetus - the same grounds we appeal to in endorsing serious moral and legal prohibitions on infanticide. Assuming that doing so does not entail any greater health risk to the mother, it is not clear that any of the woman's rights are being violated. More generally, while we take rights very seriously, we do not think of them as absolute and there are circumstances in which we think important public interests have priority. It is, for example, conceivable that we might override the property holder's rights in the above example and act to save the wilderness area, and there are other cases in which we restrict personal liberties when some important interests are at stake. If so, it is again premature of Warren to simply assume that the woman's rights will always take precedence over the interests of others in the case of abortion. Assuming a serious commitment to respecting the woman's rights reflected in the provision of open and easy access to contraception and early abortion and a clear health exception, these interests might reasonably be thought capable of justifying more general prohibitions on later abortion.

\section{IV}

I have claimed here that there is no reason to think of Marquis's argument as affording us a persuasive general argument against abortion. Any claim to plausibility he makes on behalf of his account depends essentially on the further specification of the value at stake in an FLO 
account and, given the obvious difficulties associated with the naturally suggested options Marquis considers, there is simply no reason to assume that there is a range of plausible accounts that will warrant his view. The deeper point here, I have suggested, is that any attempt to provide the detail required in a plausible FOV account will inevitably have the effect of defining moral status, and, whether we begin with this issue or confront it more indirectly in the way that FOV accounts must, the same troubling questions of inclusion and exclusion will arise.

In this sense, then, it seems to me that Warren is right in suggesting that the general question of moral status is the fundamental issue in abortion and that we would do better to begin with this more basic issue and confront it directly. In doing so we must weigh intuitions we have about the scope of moral concerns against considered judgments about the nature and extent of our moral obligations. In this respect, those of us drawn to a personhood view need to take much more seriously the problem posed by the apparent exclusion of infants and other human beings lacking the relevant cognitive capacities for personhood. When we do so, however, it seems to me that the personhood account has more to offer than Marquis or Warren acknowledge. I have argued that Marquis' use of the infanticide objection against personhood accounts of moral status underestimates these accounts and the weight that can attach to indirectly motivated moral concerns. If, however, Marquis underestimates these arguments, Warren seems guilty of overestimating their capacity to support her position. I have emphasized that the persuasiveness of the personhood response on the infanticide issue turns on the weight attributed to indirect moral concerns and have argued that any adequate response capable of motivating sufficiently serious concerns with the treatment of newborn babies and infants is likely to also permit some forms of restrictions on abortion services. If so, then just as there is no simple anti-abortion argument in Marquis, so too there is no blanket license for abortion in Warren's argument. 
Instead, the personhood account seems likely to yield a more nuanced account - one that is capable of reflecting the deep ambivalence expressed by many people about this issue who think of themselves as seriously committed to ensuring the availability of abortion but who are nonetheless also willing to impose some restrictions on the practice.

\section{Bibliography}

- Fred Feldman, Confrontations with the Reaper, Oxford University Press (New York, 1992)

- Don Marquis, "Why Abortion is Immoral", The Journal of Philosophy, Vol. 86, No.4 (April, 1989), 183-202.

- Don Marquis, "A Future Like Ours and the Concept of Person: A Reply to McInerney and Paske", Abortion Controversy: 25 Years After Roe vs. Wade, A Reader, Louis Pojman, Francis J. Beckwith, Wadsworth Publishing, $2^{\text {nd }}$ edition (Belmont, 1998)

- Jeff McMahan, The Ethics of Killing, Oxford University Press (New York, 2002)

- Gerald H. Paske, "Abortion and the Neo-Natal Right to Life: A Critique of Marquis's Futurist Argument", Abortion Controversy: 25 Years After Roe vs. Wade, A Reader, Louis Pojman, Francis J. Beckwith, Wadsworth Publishing, $2^{\text {nd }}$ edition (Belmont, 1998)

- Joel Feinberg, “Abortion”, Matters of Life and Death: New Introductory Essays in Moral Philosophy, Tom Regan, Random House (New York, 1986)

- Mary Anne Warren, "On the Moral and Legal Status of Abortion”, The Monist, Vol. 57 (1973)

1 Mary Anne Warren, “On the Moral and Legal Status of Abortion”, The Monist, Vol. 57 (1973)

2 Joel Feinberg, “Abortion”, (Feinberg, 1986, p. 256-293)

3 Gerald H. Paske, "Abortion and the Neo-Natal Right to Life: A Critique of Marquis's Futurist Argument", (pp. 361-371, Pojman)

4 Don Marquis, "A Future Like Ours and the Concept of Person: A Reply to McInerney and Paske", (pp. 372-385, Pojman) 
5 We can imagine an FOP account that thinks of the notion of higher cognitive capacities very broadly in a way that essentially collapses the distinction between it and an FOE account. This would solve the problem of marginalizing non-paradigm humans but only at the expense of incurring the more general scope problem associated with FOE accounts.

6 It is perhaps worth noting that Marquis insists elsewhere that the wrong done in killing cannot be related to the value agents assign to their existence for just this kind of reason. Analyzing Paske's view, he discusses the idea that only persons can be wrongly deprived of their futures because only persons are capable of actually valuing their futures. He explicitly rejects this position arguing:

The trouble with the "does care" view is that it does not account for why it is wrong to kill those who are suicidal, those who are just tired or bored with life, and those who are depressed. Accordingly the general wrongness of killing people cannot be dependent on the fact that the individual who is killed does have a pro attitude toward her future (Pojman, 377).

7 That this is the case seems clearly to be borne out by the literature on death and killing in which it is common to argue that harm based accounts need to be modified in light of problems like this (see, for example, McMahan (2002) and Feldman (1992)). 